\title{
ARCHIVOS Y EDUCACIÓN, UN BINOMIO INSEPARABLE
}

\author{
Aida Luz Mendoza Navarro* \\ Universidad Católica Sedes Sapientiae \\ lmendoza@ucss.edu.pe
}

Fecha de recepción: agosto de 2019 Fecha de aceptación: diciembre de 2019

Resumen: La autora destaca la información que contienen los documentos de los archivos como fuente para diversas investigaciones y sostiene que es muy útil también para los estudiantes de centros educativos a quienes se puede incentivar a desarrollarla desde edad temprana. Luego se refiere al currículo escolar como documento de archivo tipo del sistema educativo que contiene información cuya consulta para la investigación del desarrollo y evolución del sistema educativo es fundamental. Asimismo, la autora señala su firme convicción en la vinculación directa entre los archivos y la educación por lo que recomienda la integración de los archivos escolares al Sistema Nacional de Archivos debido a que en estos momentos es un sector no atendido por este. Indica, además que, cuanto más se acerquen los estudiantes a los archivos, mayor será el grado de su vinculación con la historia fidedigna que los documentos registran. Finalmente, destaca la

\footnotetext{
Aida Luz Mendoza Navarro es abogada, magíster en Gestión de Políticas Públicas y doctora en derecho. Ex jefa institucional del Archivo General de la Nación (1992-2001) y, actualmente, coordinadora del Programa de Archivística y Gestión Documental de la Universidad Católica Sedes Sapientiae. Es, también, consultora en archivos públicos y privados, así como conferencista en eventos nacionales e internacionales.
} 
necesidad de difusión de los archivos como una tarea que se debe realizar con frecuencia porque la población debe conocer la riqueza cultural e informativa que los documentos de archivo poseen, empezando por los estudiantes de los centros educativos.

Palabras clave: Educación, archivos, estudiante, documento de archivo, centro educativo.

\section{ARCHIVES AND EDUCATION, AN INSEPARABLE BINOMY}

ABSTRACT: The author maintains that the information contained in the records of the archives, as a source for various investigations and argues that it is also very useful for students of educational institution who can be encouraged from an early age in research. Then it refers to the school curriculum as a record type, of the educational system that contains information whose consultation for the investigation of the development and evolution of the educational system is fundamental. Likewise, the author points out her firm conviction in the direct link between the archives and education, and therefore recommends the integration of the school archives into the National Archives Sistem because at the moment it is a sector not attended by it. It also indicates that the more students approach the archives, the greater the degree of their connection with the reliable history that the record register. Finally, the need to disseminate the archives is highlighted as a task that must be carried out frequently because the population must know the cultural and informative wealth that the archival records possess, starting with the students of the educational institution.

KeYwords: Education, archives, student, record archive, educational institution. 


\section{Introducción}

U

na primera idea que el común de los ciudadanos tiene de los archivos es que ellos conservan los documentos que testimonian los hechos que se realizaron a lo largo de la historia de los pueblos, cuya información es útil para su reconstrucción. Toda organización, pública o privada conserva documentos de su gestión, estos deben ser atendidos por los profesionales de los archivos, quienes se encargarán de brindarles el tratamiento archivístico necesario que los documentos requieren. Los archiveros son los custodios de los archivos y aplican las técnicas necesarias para ponerlos al servicio de los diferentes usuarios.

A lo largo de la historia de los archivos, los usuarios más importantes siempre fueron los historiadores, pero desde varias décadas atrás no solo son estos profesionales los que recurren a los archivos para reconstruir el pasado. Actualmente, son diversos los interesados que investigan en ellos, y en las últimas décadas estos centros de información realizan actividades dirigidas a múltiples y diferentes usuarios, e inclusive acuden a visitarlos los estudiantes de los colegios para apreciar los documentos más importantes de la historia, donde pueden localizar documentos sobre los personajes que conocen a través de los libros. Entonces, los estudiantes de los centros educativos visitan los archivos para observar los documentos directamente en originales - exposiciones de documentos muy breves y esporádicas para no dañar los documentos - o en copias, lo que los acerca a las fuentes primarias de información donde pueden constatar documentos firmados por los personajes de la historia que ellos identifican por sus estudios escolares.

En el presente trabajo abordaremos la vinculación de los archivos con la educación a través de los documentos y trataremos de explicar cómo los archivos pueden acercarse a los estudiantes con la finalidad de que 
vayan conociendo y apreciando el valor de los documentos de archivos que testimonian el acontecer nacional.

Debemos tener muy presente que los documentos de los archivos públicos son Patrimonio Documental de la Nación que el Estado está obligado a proteger, tal como lo establece el artículo 21 de la Constitución Política del Perú. Bajo este enunciado de carácter legal tenemos que mencionar que los documentos de los centros educativos públicos forman parte de ese patrimonio, de acuerdo con el artículo 2, segundo párrafo del Decreto Supremo 022-75-ED, Reglamento del Decreto Ley 19414 de Defensa, Conservación e Incremento del Patrimonio Documental de la Nación, en tanto el indicado artículo establece que los documentos públicos no requieren de calificación expresa para ser considerados Patrimonio Documental. En tal virtud, nos referiremos a algunos documentos escolares - con mayor énfasis de los centros educativos públicos-, entre ellos el currículo escolar y su significado como documento para la investigación.

\section{Archivos y Educación}

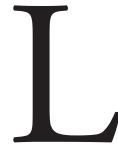

a información que contienen los documentos de los archivos, como fuente para diversas investigaciones de estudiosos de variadas áreas de conocimiento, tradicionalmente estuvo destinada a los historiadores. Actualmente, es aprovechada para una gran diversidad de profesionales, lo que hace que los archivos busquen formas o modalidades de atención que estimulen a los ciudadanos a acudir a ellos no solo para hacer investigación sino en búsqueda de los documentos útiles para atender sus necesidades legales o administrativas, sirviéndoles como fuente importante de información tanto los documentos históricos como los más 
recientes. Pero, también acuden usuarios que se acercan para ilustrarse con la información relativa a la historia social, económica, cultural o política de los países, inclusive de fechas muy recientes, siempre que de acuerdo con las disposiciones legales que rigen sobre la materia, sean de libre acceso a los ciudadanos. En esa línea, se considera la información como un derecho humano de primera generación, el cual es un postulado que recoge la Declaración Universal de los Derechos Humanos de 1948 que en su artículo $19 .^{\circ}$, establece:

Todo individuo tiene derecho a la libertad de opinión y de expresión; este derecho incluye el de no ser molestado a causa de sus opiniones, el de investigar y recibir informaciones y opiniones, y el de difundirlas, sin limitación de fronteras, por cualquier medio de expresión. (Naciones Unidas)

Recibir informaciones a partir de la Declaración en referencia se convirtió desde entonces en un derecho humano de primera generación a la que se adhirieron muchos países, entre ellos el Perú, cuyos gobiernos están obligados a cumplir.

Sobre esta disposición de carácter universal, Víctor Muhlia Melo expresa lo siguiente:

En mi modesto criterio, puedo decir que el derecho a la información es el privilegio de una libertad universal, indivisible e interdependiente que tiene toda persona sin distinción de ninguna naturaleza para investigar, recibir y difundir la 
información pública proveniente del estado, de sus dependencias, organismos paraestatales y autónomos, así como de todo sujeto que ejerza gasto gubernamental con respeto a las excepciones. $(2008,43)$

En consecuencia, la información que se encuentra en los archivos públicos puede ser difundida por toda persona, a la par que puede utilizarla para investigar o recibirla a su solicitud, ergo, todos los archivos de los organismos públicos tienen la obligación de ponerlos a disposición de los ciudadanos con las limitaciones que marca la ley respecto de los documentos que contienen información que atañe a la vida personal o privada de los ciudadanos o que guarda vinculación con la seguridad nacional.

Luego, tenemos los derechos de segunda generación y particularmente el Artículo 13 en su numeral 1 del Pacto Internacional de Derechos Económicos, Sociales y Culturales que, para efectos del presente 峝 documento, es de nuestro particular interés. El artículo señalado establece:

Los Estados Partes en el presente Pacto reconocen el derecho de toda persona a la educación. Convienen en que la educación debe orientarse hacia el pleno desarrollo de la personalidad humana y del sentido de su dignidad, y debe fortalecer el respeto por los derechos humanos y las libertades fundamentales. (Naciones Unidas) 
Este compromiso de orden internacional es ley entre los países que lo asumieron, de manera que los gobiernos deben garantizar el derecho de todos a la educación en sus diversas modalidades.

Definida la educación como un derecho de segunda generación y reconocida por el Pacto antes señalado, la Organización de las Naciones Unidas para la Educación, la Ciencia y la Cultura (UNESCO) que es el organismo internacional encargado de establecer la paz contando con la cooperación internacional en materia de educación, ciencia y cultura señala lo siguiente:

La UNESCO considera que la educación es un derecho humano para todos, a lo largo de toda la vida, y que el acceso a la instrucción debe ir acompañado de la calidad. La UNESCO es la única organización de las Naciones Unidas que dispone de un mandato para abarcar todos los aspectos de la educación (...). (UNESCO)

Si hablamos de calidad en la Educación, uno de los primeros factores para que eso ocurra, en nuestra opinión, es la necesidad de contar con buenas bibliotecas para ofrecerla con toda la información disponible para los estudiantes, de manera que pueda desarrollase el sistema educativo con las herramientas necesarias que una educación de calidad demanda. Pero también existen otros centros públicos y privados donde se conserva información primaria que, definitivamente, es muy útil para los estudiantes y que en muchos casos puede incentivarlos desde edad temprana a la investigación, a partir de una información fuente que permite crear nueva información denominada secundaria como son los libros y la diversidad de 
publicaciones que se utilizan en el sistema educativo para brindarles a los estudiantes una educación satisfactoria.

No pocas veces se confunde lo que es un archivo con la biblioteca, pues ambos conservan documentos. Sin embargo, es necesario distinguir entre ellos. El primero trata documentos archivísticos que son fuentes primarias de investigación y la segunda documentos bibliográficos que es información secundaria escrita por diversos autores, son los libros e inclusive muchos de ellos escritos a partir de información de los archivos, por lo tanto, no es lo mismo. Celia Ramírez indica la diferencia con mucha claridad:

(...) en la biblioteca tenemos un cúmulo de conocimiento, procesado ya por especialistas, en los archivos tenemos un cúmulo de información a la que hay que aplicarle métodos, criterios e hipótesis para extraer conocimiento, formularlo y transmitirlo finalmente mediante la cátedra o lo libros. (2001, p. 199)

El acceso no es igual entre bibliotecas y archivos. A las bibliotecas pueden acceder estudiantes de cualquier edad, porque además hay servicios que son dirigidos de acuerdo a la edad del lector o el nivel educativo en el que se encuentra. Por lo general, las bibliotecas públicas son de acceso a todos los ciudadanos sin mayores restricciones. En las bibliotecas privadas se pueden encontrar algunas limitaciones de acceso pero estas pueden obedecer a seguridad, conservación de los libros y colecciones, o por razones establecidas por el propietario o titular de la biblioteca; en cambio los archivos determinan excepciones de acceso, debido a la necesidad de protección de la privacidad de la información de determinadas personas, por seguridad nacional u otros temas dependiendo del archivo de que se 
trate, de acuerdo con las leyes para el acceso a la información pública y sobre protección de datos personales.

Si bien las bibliotecas son los centros a los cuales acuden los estudiantes no podemos descartar, de ninguna manera, la consulta en los archivos. La información de carácter local, preferentemente, pudiera ser muy valiosa para ellos, sobre todo para los niveles escolares superiores, así como otras formas de presentación de los documentos de archivo especialmente preparados para su exhibición que pueden suscitar interés entre los estudiantes de diversas edades.

\section{3. ¿Qué es un archivo y qué es un documento de archivo?}

$\mathrm{P}$ odemos encontrar diversas definiciones de archivo y documento de archivo en la doctrina sobre la ciencia Archivística, las hay variadas. Antonia Heredia, destacada archivera española, luego de mencionar varias definiciones indica las acepciones de institución y sistema y luego las desarrolla como sigue:

Institución o sistema responsable de las funciones integradas en la gestión de documentos y en la administración de Archivos de una organización.

Institución responsable de la custodia y servicio de los documentos de conservación permanente de una institución, de un territorio o de una circunscripción administrativa.

Institución responsable de la custodia y servicio de los documentos en cada una de las edades del ciclo vital. (2011, p. 46) 
En la definición encontramos el significado de archivo como el lugar donde se encuentran los documentos y como el sistema que desarrolla las funciones de la gestión y administración de archivos. Podemos llegar a la conclusión que se refiere al local del archivo, al conjunto de documentos que conserva y a las actividades que se ejecutan en el archivo de acuerdo con las funciones archivísticas.

Para Antonia Heredia, documento de archivo es:

Unidad de información estructurada y contextualizada, registrada en cualquier soporte, producida por un agente productor en el ejercicio de sus funciones y actividades atribuidas, testimonio y prueba de una o varias acciones cuya relación entre ellas determina dicha unidad. (2011, p. 91)

De acuerdo con la definición de Antonia Heredia, el documento de archivo es testimonio y prueba y si nos ceñimos a la idea de información para la educación tenemos que centralizarnos en su calidad de testimonio cuando se trata de poner en conocimiento ciertos hechos sucedidos a lo largo del pasado histórico y también de la historia reciente; y en su calidad de prueba de documentos que la Educación demanda para el sistema como tal, donde encontramos una gran y múltiple variedad. Esta puede ir desde los documentos de gestión educativa de los centros administrativos del sistema de la Educación en un país, hasta los que conservan los archivos escolares propios de la gestión administrativa y educativa de cada centro educativo. Gracias a ello, podemos destacar los que son útiles a los estudiantes para 
identificarse como ciudadanos o como miembros de un determinado centro educativo. Unos y otros son útiles para el desarrollo del sistema como para los alumnos.

Los documentos que generan todo el sistema educativo tienen determinadas características y es distinto al de otros sectores de actividad, existen series y tipos documentales específicos como certificados de estudios, registros de matrícula, actas, etc.; todos documentos de archivo que deben ser trabajados de acuerdo con las técnicas propias de la Archivística para garantizar su conservación. Estos documentos son útiles para el normal desarrollo de las actividades del centro educativo, como para los propios alumnos, además de ser necesarios para cumplir con sus obligaciones y atender los derechos de sus usuarios.

\section{Documentos de Archivo en el Sistema Educativo Escolar}

L os documentos de archivo recogen la gestión realizada de toda una organización, los documentos se van generando día a día de acuerdo con las funciones y actividades desarrolladas. Un centro educativo cualquiera sea su nivel, público o privado, hace gestión administrativa y gestión educativa durante el ejercicio de sus funciones. Por lo tanto, va produciendo documentos de archivo que deben conservarse para responder a sus derechos y obligaciones.

Los documentos se van generando permanentemente desde el primer día que el centro educativo inicia sus actividades, y quizás antes porque para empezar a funcionar debe realizar trámites ante las instancias administrativas correspondientes para obtener la licencia de funcionamiento 
y todas las autorizaciones que demanda la normativa administrativa del lugar donde se ubicará, cuando es de origen privado. Si se trata de un centro educativo público, igualmente, antes del funcionamiento se realiza un procedimiento administrativo de creación donde se van sumando una serie de documentos para finalmente iniciar sus actividades. Todos estos documentos van a un determinado espacio (archivo) donde se conservan con el fin de utilizarlos como referencia, antecedentes o para probar la gestión y se van sumando a lo largo de su existencia, además de otros documentos como producto de las fiscalizaciones o controles que deban aplicarse para vigilar que se ofrezca un servicio adecuado a los estudiantes y para cumplir con las normas gubernamentales de la función pública.

Los documentos producidos por una institución deben ser organizados para poder servirlos con la inmediatez que la consulta exige y si se encuentran en un sistema digital, del mismo modo, deberá contar con todas las facilidades y acceso para la inmediata consulta. Este capital intangible del centro educativo debe gozar de todas las medidas de prevención para evitar su pérdida debido a que son testimonios de la gestión realizada, pero también pruebas para demostrar determinados hechos cuando las circunstancias así lo ameriten.

Paralelamente al servicio de los documentos de archivo de un centro escolar, para la demostración de hechos o para probar derechos y responder a las obligaciones, la utilidad de los documentos de archivo no concluye con esos servicios, si partimos del beneficio de los documentos para la investigación sobre esas fuentes tan valiosas de información como son los archivos, por parte del personal docente y también de los alumnos de los niveles superiores educativos que gozan de un mayor nivel de conocimientos que les permite el análisis e interpretación de fuentes de información de 
los archivos. Al respecto, Celia Ramírez, sobre la investigación en archivos, señala: "El trabajo sobre un tema basado en fuentes primarias lleva necesariamente a un conocimiento más amplio, más profundo e incluso más acertado. Nueva información puede incluso destruir viejos paradigmas o por lo menos ponerlos en duda” (2001, p. 201).

Buscar el acercamiento de todo tipo de estudiosos o investigadores hacia los archivos es propender a la creación de nuevos conocimientos. Las fuentes de información primarias de los archivos son información privilegiada para los investigadores, consecuentemente, por qué no incentivar la investigación sobre estas fuentes desde edad temprana. Los estudiantes de los niveles superiores de estudios escolares que ya están próximos a dejar las aulas para pasar a los estudios universitarios, harían muy bien en investigar sobre documentos de archivos debido a que encontrarán la información tal y como sucedieron los hechos, no como los interpretó el autor de un libro o cómo influyó su apreciación personal sobre ellos. Por lo tanto, los archivos enriquecen el conocimiento porque es información primaria incuestionable, sobre la cual los estudiantes podrán conocer la realidad directamente y comprobar o llegar a extraer otras conclusiones de las que conocen por los libros de consulta con los que estudian. Acudiendo a las fuentes primarias de información — de los archivos—, muchas veces se ha comprobado que los hechos no fueron como nos contaron en los libros.

Los archivos históricos, por lo general, restringen el acceso a los estudiantes de etapa escolar para investigación por razones de conservación de los documentos, en el entendido que un estudiante en edad escolar no asumirá los cuidados necesarios que se exigen para la consulta de documentos originales en papel. Sin embargo, con el avance de la tecnología informática ahora es posible que ellos puedan acceder a los documentos digitalizados con 
lo cual se conserva y protege el documento original respecto de su integridad y se facilita el acceso e inclusive su diseminación a través de imágenes por Internet.

Entre los últimos años del sistema educativo escolar, sería muy conveniente orientar a los estudiantes, entregándoles pautas sencillas para que se inicien en la investigación, adicionalmente los centros educativos podrían hacer convenios con algunos archivos históricos o de gobiernos locales para promover la investigación. De esta manera, al llegar a la universidad, donde la investigación es un elemento fundamental para su formación desde el inicio de la carrera, los estudiantes al transitar hacia la universidad tendrían los elementos básicos para desarrollar breves investigaciones al empezar su carrera profesional.

\subsection{El currículo escolar como documento de archivo}

Aunque el currículo escolar no es estrictamente un documento de archivo de centro educativo, sino del organismo encargado de ese sector que es el Ministerio de Educación, nos referiremos a este documento por considerarlo de gran valor informativo para el sistema educativo.

Para Aztiz Fernanda, el curriculum escolar obedece a una corriente teórica para la organización de la educación masificada que es responsabilidad de los estados nacionales modernos y sujeto a fundamentos ideológicos y filosóficos que cambian en el tiempo donde están presentes los valores sociales que dominan en un estado-nación, las costumbres culturales, los ciudadanos según su formación, el factor económico, los regímenes políticos, como también la necesidad de nuevos conocimientos para el desarrollo de la población en edad escolar y su integración a la adultez (2014, p.4). 
Un documento de archivo testimonia, prueba y reconstruye el pasado nacional, desde ese punto de vista el currículo escolar viene a ser un documento con relevante información para entender la evolución de la educación en un estado-nación, pero también para obtener información respecto de diversas áreas del acontecer nacional como sociedad. Si hacemos retrospección de los currículos escolares de las últimas décadas del sistema educativo en nuestro país podemos visualizar que en las reformas que se han llevado a cabo se comprueba aspectos de la vida social, económica, cultural y política, además de su incidencia en el contexto internacional, principalmente, del campo socio-económico y político. En estos momentos tenemos temas que antes no se abordaron, como la inclusión social, el medio ambiente, el enfoque de género, la incidencia de las Tecnologías de la Información y Comunicaciones (TIC) que vienen produciendo grandes cambios en el sistema educativo.

Aztiz señala una serie de derechos relacionados con la inclusión social:

(...) el efecto directo de la nueva narrativa mundial que enfatiza la inclusión en un mundo altamente globalizado, es la intensificación de los derechos colectivos (reivindicaciones de género y etnias, por ejemplo) como el aumento de los derechos individuales, especialmente en el ámbito de los derechos culturales. El reconocimiento y exaltación de la diversidad lingüística es un ejemplo claro de esta dualidad. La recuperación de las lenguas de grupos minoritarios y su inclusión en el curriculum escolar reafirma el derecho del hablante a reivindicar su historia, su idioma y su cultura, y que los mismos sean 
valorados y reconocidos por la sociedad en su conjunto (nacional, subnacional y global). Si bien dichos cambios reafirman los derechos lingüísticos de los educandos y de su identidad cultural, la afirmación implícita que se desprende es dual. (2014, p. 7)

El currículo escolar, siguiendo a Aztiz, es un documento que ofrece importante información y como documento de archivo su consulta para la investigación histórica del desarrollo y evolución del sistema educativo es fundamental. El curriculum, no es un documento de archivo, individual o aislado, ha sido producido en un determinado contexto, como todo documento de archivo. Forma parte de otros documentos que integran la versión final, como son los antecedentes, opiniones, consultas, dictámenes, fundamentos técnicos y teóricos sobre el tema, posiciones políticas, sociales o educativas, documentos que evidencian la socialización del currículo a través de eventos académicos, foros, etc., formando un expediente — para

๙ decirlo en términos menos técnicos, un conjunto de documentos-, es de una riqueza de información muy valiosa para la reconstrucción del acontecer nacional en el campo de la Educación.

\subsection{Aproximaciones a la situación de los documentos de los centros escolares}

Los documentos más importantes que un centro escolar posee pueden tener similitud con los de cualquier otra organización, sin embargo, podríamos referirnos a algunos en particular que consideramos específicamente necesarios.

La Archivística denomina documentos esenciales a todos aquellos que son necesarios a cualquier organización, sin los cuales esta tendría 
muchas dificultades para continuar su funcionamiento o responder a las eventuales obligaciones administrativas o jurisdiccionales, entre estos documentos esenciales, según Barboza Saia y Castro García, refiriéndose al Decreto No 200 de 22 de enero de 1962 del Ministerio de Educación y Cultura /MEC-DEM de Sao Paulo, Brasil, que establece el expurgo de papeles de valor transitorio inútiles para la conservación y ordenación de los documentos esenciales, señalan:

(...) fueron considerados documentos esenciales las actas generales de exámenes de admisión, las actas finales, las actas de exámenes de segundo período, de exámenes especiales, revalidación, adaptación, fichas de transferencia, de notas y otros documentos que registraron el desempeño del alumno, que prueban la realización de sus actividades. Básicamente podemos entender como documentos preservados, todos aquellos que pueden ser encontrados en el proceso /prontuario del alumno. El resto de documentos como diarios de clases, recortes de periódicos sobre la Escuela, cuadernos de los alumnos, diarios de profesores, entre otros, eran considerados no esenciales, pudiendo ser quemados. (2014, p. 164)

Barbosa, refiere una experiencia de valoración de documentos de archivo escolar que es un proceso archivístico que consiste en determinar el valor de los documentos primario o secundario, y establecer una Tabla de Retención de Documentos que permite eliminar los documentos innecesarios al término de su vigencia y conservar indefinidamente los que son de valor histórico. No analizaremos si corresponde o no la incineración 
que afirma de los documentos referidos a diarios de clases, diarios de profesores, etc. Lo que destacaremos es la necesidad de mantener el acervo documental organizado para el servicio tanto de los docentes como de los alumnos.

La organización de los documentos es una de las tareas fundamentales en Archivística, cada institución debe mantener sus documentos en condiciones de poder atender las necesidades de información de manera inmediata. Conocemos la precariedad de muchos centros escolares en nuestro país, con locales inapropiados para el desarrollo de las clases escolares y consecuentemente para las tareas de gestión educativa. En esos centros, sin duda, los documentos generados como resultado de las actividades del centro escolar se encuentran en riesgo de destrucción.

Nos preguntamos, respecto de los centros escolares públicos, ¿cuántos a nivel del país cuentan con las condiciones mínimas para garantizar la conservación de los documentos que producen?, ¿existe personal capacitado o formado para atender los archivos de los centros escolares? No lo sabemos. Si tenemos en cuenta los dos Censos del Sistema Nacional de Archivos (SNA), aplicados por el Archivo General de la Nación (AGN), organismo rector de los archivos en el Perú, tanto el Censo de 1997 como del 2014 no alcanzaron a los archivos públicos escolares. Nótese que solo en Lima existen colegios que deben conservar valiosa información de diferentes personajes de la cultura, las ciencias, la historia etc., que estudiaron en colegios como Nuestra Señora de Guadalupe, Alfonso Ugarte, Teresa González de Fanning, Mercedes Cabello de Carbonera, etc., solo para citar algunos colegios emblemáticos. Es una información que el AGN no tiene y esos documentos forman parte del Patrimonio Documental de la Nación, ¿cuántos documentos importantes se han perdido? Si no se percibe la 
importancia de los documentos de ese sector del Estado, que es muy amplio, no se está en capacidad de protegerlo. En consecuencia, no existen cifras estadísticas sobre la situación en la que se encuentran los archivos escolares en nuestro medio. Esta es una tarea pendiente que el AGN junto con el Sector Educación deberían emprender desde el ámbito de la Archivística, en algún momento. Tenemos la convicción de la vinculación directa entre los archivos y la educación como lo venimos afirmando a lo largo del presente trabajo, por lo tanto, integrar a los archivos escolares al SNA debe ser una decisión impostergable.

Siendo de gran importancia los centros escolares mencionados, nos preguntamos lo siguiente: ¿se conservará algunos exámenes de los personajes más destacados que cursaron estudios en algunos de ellos? o documentos como pruebas estandarizadas aplicadas y sus resultados, las boletas de calificaciones, expediente por alumno, documentos sobre la disciplina o sanciones que hayan recibido los estudiantes, así como felicitaciones, encuestas, cuestionarios, documentos que evidencien el proceso de matrícula o traslado a otro centro educativo de los alumnos, etc. Son series y tipos documentales variados como en toda organización que demandan un tratamiento profesional archivístico para su conservación, tanto para el propio centro educativo como para sus usuarios y para la sociedad en general.

\section{Los archivos en apoyo de las actividades pedagógicas}

L os archivos con la rica información que poseen, sobre todo los archivos nacionales o generales de la Nación que albergan documentos provenientes de los diferentes sectores de la administración pública, 
deben comprender dentro de sus actividades de difusión a los escolares en coordinación con los centros educativos. Algunos de los archivos citados cuentan inclusive con documentos de origen privado de importantes personajes de la historia y de fechas significativas que registran hechos históricos trascendentes para los países. Un ejemplo concreto es el Taller que realizó en el Archivo Nacional de Chile el 22 de junio del 2016 denominado "Uso y manejo de fuentes documentales para la enseñanza de la historia en Educación Básica y Media” para docentes de nivel escolar. El objetivo fue: “(...) generar un espacio formativo para profesores de historia, geografía y ciencias sociales de Enseñanza Básica y Media de establecimientos educacionales del país sobre el uso y trabajo con fuentes documentales en el aula" (Archivo Nacional Chile, 2016).

Muy escasos son los archivos nacionales o generales de la Nación que han realizado actividades en apoyo a la educación mediante exposiciones de documentos históricos de personajes que los estudiantes de nivel escolar identifican muy bien. Cuadros, sobre el acercamiento de esos archivos a alumnos de colegio, manifiesta:

Sería interesante confrontar esta observación con la situación actual para percibir si los archivos fueron dotados a lo largo de 25 años de estructuras adecuadas, espacios para acoger al alumnado, recursos humanos suficientes para acompañar y promover las actividades, etcétera, además de constatar si surgieron otras necesidades, como la exigencia de nuevos recursos y tecnologías, tareas específicas de las TIC que van más allá de los conocimientos de los archiveros. (2015, p. 270) 
Ramón Alberch refiere que en el año 1950 Francia pone en ejecución los servicios educativos en los archivos nacionales para enseñar historia en la Escuela y, parafraseando a Martín Gonzáles, señala que a partir de entonces se iniciaron actividades dirigidas a los escolares valorando los archivos como recursos didácticos. Esto ha contribuido a su apertura y difusión beneficiando a los métodos pedagógicos que favorecen la observación, además de la experimentación de los alumnos para afianzar el desarrollo de la historia local (2001, p. 57).

Alberch, se refiere a la relación de los centros educativos con los archivos parafraseando a Canela, Cuñé y Salat como sigue:

Para los centros educativos es básico enriquecer el proceso de aprendizaje del conjunto de las ciencias sociales a través del contacto con las fuentes documentales, suscitar la reflexión y despertar el sentido crítico de los alumnos a través del acercamiento a su realidad más inmediata a través de los documentos conservados en los archivos y hacerles descubrir la relación entre los grandes hechos de la historia y los de su ámbito local. (2001, p. 61)

Cuanto más se acerquen los estudiantes a los archivos, mayor será el grado de su vinculación con la historia fidedigna que los documentos registran. Por otro lado, enriquecerán su bagaje cultural mediante la información directamente capturada de la fuente primaria de información.

Alberch y Hernández señalan que los estudiantes, para confirmar los hechos históricos: “(...) es básico, que los alumnos puedan disponer de copias o facsímiles de los documentos para analizarlos y llegar unas 
conclusiones que les permitan descubrir aspectos de su pasado" (2001, p. $62)$.

Los facsímiles y todo tipo de materiales que reproduzcan los documentos con sus características originales, son muy apreciados por los estudiantes, por ejemplo, visualizar la firma de un personaje de la historia, con seguridad los impresionará.

\subsection{La Ley General de Patrimonio Cultural de la Nación en la educación, difusión y promoción cultural: los archivos}

Los diversos servicios educativos que ofrecen los colegios son utilizados para actividades pedagógicas cuyos usuarios son los estudiantes de los centros educativos y su propósito es afianzar su educación. Dentro de ellos no son muy conocidos los que se pueden realizar a través de los archivos. Estos desde hace buen tiempo dirigieron su atención hacia los escolares desarrollando actividades para ese sector de la población e incluyeron materiales específicos teniendo en cuenta que es un público diferente al que tradicionalmente sirvieron los archivos. De esta manera los archivos prepararan programas culturales siguiendo determinadas estrategias para acoger a todos los públicos, extendiendo sus servicios a público diverso en edades, niveles y necesidades de educación (Cuadros, 2015, p. 267).

La sociedad en general conoce muy poco lo que significan los archivos para un país y para los ciudadanos como personas individuales. Las ideas que se tiene del archivo son en su mayoría erradas, por lo que su difusión, apelando a las múltiples modalidades que existen para llegar a los ciudadanos, debe constituirse en parte de las funciones de los grandes 
archivos nacionales principalmente. No más archiveros encerrados en sus cuatro paredes, estos deben salir a decir en voz alta qué es un archivo.

Las actividades y estrategias que pueden desarrollar los archivos, sin duda, contribuyen a su difusión y a poner de relieve su importancia en la educación escolar. Pero, además, con la Ley 28296 General de Patrimonio Cultural de la Nación en lo que se refiere a la Educación, la Difusión y la Promoción Cultural, se establece:

Artículo 51.1: El Instituto Nacional de Cultura, la Biblioteca Nacional y el Archivo General de la Nación y demás organismos vinculados a la Cultura velarán para que se promueva y difunda en la ciudadanía la importancia y significado del Patrimonio Cultural de la Nación como fundamento y expresión de nuestra identidad nacional.

Los medios de comunicación estatal están obligados a difundir el Patrimonio Cultural de la Nación en sus diferentes expresiones. Artículo 51.2 Los organismos competentes promueven y coordinan con los medios de comunicación y demás entidades públicas y privadas para estimular y difundir el respeto y la valoración del Patrimonio Cultural de la Nación.

Artículo 52.- Contenidos curriculares Es obligación del Instituto Nacional de Cultura, la Biblioteca Nacional y el Archivo General de la Nación, según corresponda, proponer al Ministerio de Educación los contenidos curriculares sobre la materia, para ser incluidos en el plan de estudios de todos los niveles de la educación nacional. (Congreso, 2007) 
De acuerdo con la ley, los organismos de cultura deberán promoverla cada uno a partir del patrimonio cultural que conserva. Para el caso que nos ocupa, el AGN es el encargado de programar las actividades relacionadas con ese propósito. La difusión podrá realizarla por diferentes medios incluyendo el uso de las TIC que en estos tiempos es la mejor manera de llegar a los usuarios de manera amplia, como es el caso de los estudiantes a nivel nacional. Por otro lado, tiene el encargo de proponer al Ministerio de Educación los contenidos curriculares sobre el Patrimonio Documental Archivístico para cada uno de los niveles de educación.

La elección de los contenidos curriculares por niveles de educación es una tarea muy importante que el AGN deberá coordinar con los docentes que son los especialistas en didáctica educativa, quienes conocen la metodología de enseñanza. Ellos podrán orientar la mejor manera de llegar a cada nivel con el fin de que el estudiante pueda entender a cabalidad el mensaje que se pretende sobre el conocimiento de los hechos históricos a través de los documentos de archivo, aspectos sobre la utilidad de esos documentos, el valor de patrimonio que tienen para el país y la protección que se les debe otorgar para garantizar su conservación para las generaciones futuras.

Los contenidos llevarán, además, el propósito de que los estudiantes puedan entender, de acuerdo con los testimonios o documentos, cómo se produjeron los cambios sociales e inclusive podrán visualizar los documentos que reflejan la historia de la educación en nuestro país; o cómo se enseñaba hace décadas atrás y podrán contrastar las diferencias con la situación actual. De ese modo llegarán a entender que los cambios operan en muchos aspectos e involucran a varios actores en el espacio educativo como son los docentes, 
los estudiantes, las autoridades educativas, los colegios como instituciones, las políticas gubernamentales sobre educación, etc.

\subsection{Actividades de difusión de los archivos}

En nuestro medio son muy escasas las actividades que se realizan relacionadas con los archivos y los centros escolares de estudios en sus niveles primario y secundario. Alberch, Boix, Navarro y Vela, en Archivos y cultura: manual de dinamización (pp. 57-84), dedican un amplio espacio al Servicio Educativo a partir de los archivos. Ellos presentan varias actividades que muy bien pueden ser desarrolladas por los archivos. A continuación, mencionaremos algunas:

- Talleres: Es una tarea entre el docente y el archivero, debiéndose planificar a partir de los contenidos curriculares, que pueden ser acompañados de cuestionarios para resolver por los estudiantes. Se debe prever los aspectos de logística y la organización de la actividad. Los autores recomiendan que antes de preparar la actividad los archiveros vayan a la escuela con el fin de explicar a los estudiantes las actividades que realiza un archivo, tales como: la historia del archivo, sus funciones, información sobre los fondos documentales, cómo se efectúa el tratamiento de los documentos, etc.

- Talleres de historia: Tiene por finalidad mostrar a los estudiantes los documentos que son fuente informativa de los libros de historia que ellos conocen, pero sobre todo valorar el servicio que los archivos brindan. La diversidad de los documentos de archivo 
es inconmensurable debido a que tratan sobre toda la gestión de una organización. Los autores, recomiendan que después de concluido el taller se realice un debate que comprenda tomar una posición y adopción de decisiones. Inclusive se puede preparar una dramatización a partir del contenido de los documentos, por ejemplo, tomando un caso que se refleja en el procedimiento registrado en un determinado expediente.

- Talleres tecnológicos: Se requerirá de una infraestructura adecuada para realizar un taller de reprografía para la reproducción de algunos documentos, sobre la base de algunas pautas muy sencillas de restauración y conservación de documentos, etc. (2001, pp. 70-72)

Las actividades para ser entendidas para los estudiantes deben ser muy atractivas, e inclusive se prepararán por niveles de escolaridad. No será lo mismo proyectar una actividad para niños de nivel primerio a uno de nivel secundario. Con los niños más pequeños será necesario idear algunos juegos que, por supuesto, garantice que los documentos no se ponen en riesgo. En cuanto a los estudiantes de secundaria, se pueden hacer actividades que implique un debate sobre los documentos que han observado o sobre el contenido de un expediente de un personaje de la historia, mejor aún si se trabaja con varios expedientes de diversas épocas.

Los archivos históricos posiblemente son más ricos en cuanto al significado de los documentos a mostrar. Sin embargo, podemos encontrar igualmente documentos muy interesantes de fechas más recientes o de personajes que les son conocidos a los estudiantes y que no están bajo las restricciones de acceso a la información, como de literatos, políticos, funcionarios públicos, artistas, etc. 
Una forma de difusión de los documentos de archivo histórico más sustancial es la preparación de facsímiles, aun cuando su costo es elevado en tanto se tiene que reproducir con gran exactitud los elementos del documento, incluyendo trazos, manchas si las hubieres, anotaciones, etc., pero son de gran utilidad para el conocimiento de los estudiantes de nivel secundario, porque pueden manipular los documentos y sentir como si tuvieran en sus manos los originales. Alberch, Boix, Navarro y Vela refieren que en Francia desde 1950 se prepararon carpetas didácticas que complementaban las exposiciones de documentos con fines pedagógicos, y en el Reino Unido fueron de gran éxito en el año 1963. Citando a Cook (1985), los autores señalan que a partir de esta fecha se concretaron las denominadas "unidades de enseñanza de archivos" mediante facsímiles de los documentos que, además, contaban con material explicativo para el profesor donde se indicaban los objetivos de la unidad (2001, p. 74).

El AGN desde los años 80 inició la presentación de muestras documentales en exposiciones temáticas, la primera exposición que se realizó por el año 1981, inaugurada un 4 de noviembre de ese año fue sobre José Gabriel Condorcanqui, Túpac Amaru II y así continuó año a año presentando muestras de los valiosos fondos documentales que custodia, invitando a los colegios para visitar las exposiciones documentales por un determinado espacio de tiempo. Más adelante, el 12 de marzo de 2018, el AGN puso en ejecución un Proyecto Educativo cuya primera actividad fue reunirse con un grupo de docentes de la UGEL 03. A ellos se les condujo al recorrido planteado para los escolares en su visita al AGN. La propuesta pedagógica pretende crear una alianza estratégica con docentes para llegar a las escuelas, teniendo como propósito sensibilizar a la población sobre la importancia del Patrimonio Documental Archivístico. 
El proyecto consta de las siguientes fases: la primera consiste en reuniones con docentes para conocer la información que se les ofrecerá a los estudiantes; la segunda, es la programación de visitas de los archiveros a los centros escolares; en la tercera fase, los estudiantes acudirán a las instalaciones del AGN, mientras que en la fase final se realizarán trabajos en el aula.

El AGN se encargará de preparar los materiales didácticos para vincular esta propuesta con la currícula escolar, y para contribuir con el proceso educativo en el conocimiento del Patrimonio Documental Archivístico (AGN, 2018).

La difusión de los archivos es una tarea que se debe realizar con frecuencia porque la población debe conocer la riqueza cultural e informativa que los documentos de archivo poseen. Si bien los archivos nacionales y archivos generales de la nación, realizan actividades de difusión como parte de su proyección hacia la sociedad, es también necesario que la difusión y particularmente las exposiciones documentales se realicen desde otros espacios, como las municipalidades. Los gobiernos locales son los más próximos a la población, ellos conservan importantes documentos que recrean la historia de la localidad de su ámbito geográfico.

Muchos documentos de diferentes clases son, con toda seguridad, de interés para la población. El documento de archivo no solo es el textual, también son parte del archivo las fotografías, los planos, las cartas geográficas, vídeos, etc., todo ese material documental puede ser presentado en una muestra documental. Es posible preparar una exposición con documentos que sean atrayentes para los escolares, siempre por niveles educativos para llegar mejor al estudiante. Las fotografías, por lo general son las que mejor ilustran una muestra documental. Los especialistas en museología conocen 
las técnicas más adecuadas para exhibir documentos, de manera que se muestren fácilmente entendibles para la población escolar.

La riqueza documental de nuestro país merece ser conocida desde la etapa escolar, solo de esa manera tendremos generaciones que aprecien y entiendan el significado del Patrimonio Documental de la Nación. Sin embargo, es muy poco lo que se hace en ese sentido. Es necesario abrir espacios entre los archivos históricos de los gobiernos locales, de las instituciones representativas de la cultura de nuestro país, para lograr un trabajo de conjunto con los docentes con la finalidad de llegar a los estudiantes, motivándolos a crear una vinculación con los hechos del pasado registrados a través de los documentos de archivo.

Es necesario trabajar, como medio de difusión, folletos o comunicados breves para transmitir información muy puntual de la riqueza documental, acompañando fotos de documentos trascendentes que los alumnos puedan identificar fácilmente.

Alfonso Rubio destaca las exposiciones de documentos de archivo como un interesante vehículo de difusión de los documentos:

Hoy en día, cuando comunicar parece indispensable, las exposiciones mejoran la imagen tradicional que la ciudadanía tiene de un archivo. Han de ser un medio y no un fin en sí mismas para:

- Difundir el trabajo del archivo y los fondos documentales conservados en él

- Posibilitar enriquecer los fondos con nuevos ingresos de fondos privados 
- Demostrar la utilidad de la investigación en los archivos

- Explotar el servicio de archivo en términos de empresa e igualmente en términos políticos. (2016, p. 47)

Las exposiciones documentales son actividades que los archivos nacionales y generales de la Nación realizan con cierta frecuencia. Pero también es necesario que otras instituciones que custodian valiosos documentos de archivo los difundan de la misma manera u optando por preparar folletos con imágenes de los documentos y material fotográfico de la localidad para que los estudiantes aprendan a apreciar su cultura.

Los archivos no son organizaciones que el común de la población conoce a cabalidad. La idea generalizada, para decirlo una vez más a riesgo de ser reiterativo, es la de un lugar lúgubre, lleno de documentos antiguos que nadie usa, con o sin alguien que los atienda. Con esta imagen que se tiene de los archivos difícilmente podemos despertar el interés de la población. No se aprecia lo que no se conoce, por lo tanto, las exposiciones de documentos son un excelente vehículo para dar a conocer lo que conserva un archivo. Estas deben ir acompañadas de breves y claras explicaciones sobre lo que es y significa un archivo para los ciudadanos.

$\mathrm{Al}$ conocer cómo funciona un archivo, cómo conserva los documentos y porqué se valoran, los ciudadanos se verán identificados con los testimonios del pasado y, como señala Rubio, se procura nuevos ingresos de documentos, incluso provenientes de archivos privados. Otro objetivo puede ser la investigación sobre fuentes documentales de archivo: cuántos historiadores podrían obtener valiosa información en los gobiernos locales para la reconstrucción del pasado de la localidad, cuántos vecinos conocen los primeros años de la fundación de su localidad. Estos y otros temas de 
interés pueden ser resueltos o respondidos mediante los documentos de archivo. Igualmente, se requiere que los jóvenes se inicien en la investigación lo más temprano posible. Los archivos siempre serán la mejor fuente de información para esa tarea porque conservan los documentos originales y auténticos. Por ello, los archiveros en trabajos conjuntos con los docentes de los centros escolares pueden apoyar el inicio de investigaciones sencillas que los estudiantes podrían realizar a partir de los documentos de los archivos para la reconstrucción de la historia de su localidad.

Aprovechando el desarrollo de las TIC, es posible realizar exposiciones virtuales de documentos, estas llegan de manera más inmediata a los estudiantes. La digitalización de los documentos integrantes del patrimonio documental en estos tiempos de expansión de las TIC ayuda considerablemente a la difusión de los documentos, con la ventaja de proteger los originales de riesgos de deterioro, hurto $\mathrm{u}$ otros actos que los pueden dañar.

En otra perspectiva, un programa de visitas a las organizaciones donde se conserva documentos vinculados a la identificación personal, a la zonificación de los domicilios donde habitan los escolares, documentos de catastro, $\mathrm{u}$ otros en los cuales pueden identificar a sus familiares o a ellos mismos será relevante para emprender una verdadera concienciación sobre el valor de los archivos y el derecho que tiene todo ciudadano al acceso a la información. De esta forma, el valor de los documentos de archivo que los estudiantes pueden apreciar no solo estará en los documentos más antiguos sino también en los documentos recientes. Una exhibición de determinada información desde una base de datos, posiblemente será atractiva a un joven que, además, está familiarizado con el uso de las TIC. 
Actualmente es posible utilizar diversas aplicaciones informáticas. Algo como una vertiente interactiva de documentos sobre identificación ciudadana dialogante, entre la organización que conserva los documentos y los estudiantes podría ser interesante, donde además ellos podrán constatar que la información de un archivo no solo está en el soporte papel, sino que se encuentra ahora también en otros medios, el digital, que ellos conocen muy bien. Desde las muestras documentales, en soporte de papel o en medio electrónico, comprenderán que los archivos son información que es útil al ciudadano y aprenderán a apreciarla.

\section{Conclusiones}

T os documentos de archivo son fuente valiosa de información para la investigación, consecuentemente, de gran utilidad para los estudiantes de los centros educativos a los que se debe estimular desde edad temprana en la investigación.

El currículo escolar es un documento de archivo, el cual ofrece importante información para la investigación histórica del desarrollo y evolución del sistema educativo. Forma un expediente que contiene antecedentes, opiniones, consultas, dictámenes, fundamentos técnicos y teóricos sobre el tema, posiciones políticas, sociales o educativas por lo que ofrece valiosa información para la investigación.

La vinculación directa entre los archivos y la educación, tanto para la investigación temprana de los alumnos de centros educativos como para ilustrarlos en la riqueza documental del país través de su difusión, logrará 
que este sector de población reconozca el valor del Patrimonio Documental de la Nación.

La integración de los archivos de los centros escolares es una tarea que se debe emprender entre el Archivo General de la Nación y el Ministerio de Educación para proteger los documentos que se generan en la gestión administrativa y educativa.

\section{REFERENCIAS}

Archivo Nacional-Chile. (2016). Los archivos como aporte a la Educación. Recuperado de https://www.archivonacional.gob.cl/616/w3article-63063.html?_noredirect=1

Archivo General de la Nación, Perú. (2018). Noticias. Recuperado de http:// agn.gob.pe/portal/noticia/1522711763-nuevo-proyecto-educativodel-archivo-general-de-la-nacion

Alberch, R., Boix Llonch, L., Navarro, N., \& Vela, S. (2001). Archivos y cultura: manual de dinamización. Gijón, España: Trea.

Aztiz, M. F. (2014). El Curriculum escolar y su abordaje desde la teoría de la sociedad mundial: revisión y prospectiva. Revista Académica Archivos Analiticos de Politicas Educativas, 22(25), 1-13. Recuperado de https://www.redalyc.org/articulo.oa?id=275031898047

Barboza Saia, I., \& Castro García, E. J. (2014). El acervo escolar, manual de organización y cuidados básicos. Paradigma Revista de Investigación 
Educación, 21(24), 161-187. Recuperado de https://www.lamjol. info/index.php/PARADIGMA/article/view/1697

Cuadros, J. (2015). Los servicios educativos de los archivos. Journal for Educators, Teachers and Trainers, 6(1), 265-286. Recuperado de https://archivofsierrapambley.wordpress.com/2016/05/17/losservicios-educativos-de-los-archivos/

Heredia, A. (2011). Lenguaje y Vocabulario Archivísticos, algo más que un diccionario. Sevilla, España: Junta de Andalucía.

Ley 28296. Ley General de Patrimonio Cultural de la Nación. Congreso de la República. (2007). Recuperado de http://www2.congreso.gob. pe/sicr/cendocbib/con2_uibd.nsf/562A9CC-F932F0F62052577E 300711E65/\$FILE/2Ley_28296.pdf

Muhlia Melo, V. \& Peña Campuzano, G. (2008). El derecho de acceso a la información, como un derecho humano. Memoria Tercera Semanal de Transparencia. Recuperado de http:// contraloriadelpoderlegislativo.gob.mx/Revista_Rc_et_Ratio/Rc_ et_Ratio_1/Rc1_3_Victor_Muhlia_Melo.pdf

Organización de las Naciones Unidas para la Educación la Ciencia y la Cultura. (s.f.). Sobre la Unesco. Recuperado de https://www.ohchr. org/sp/professionalinterest/pages/cescr.aspx

Organización de las Naciones Unidas para la Educación la Ciencia y la Cultura. (s.f.). Declaración Universal de los Derechos Humanos. Recuperado de http://www.unesco.org/new/es/santiago/education/ Organización de las Naciones Unidas para la Educación la Ciencia y la Cultura, Pacto Internacional de Derechos Económicos, Sociales y Culturales Adoptado y abierto a la firma, ratificación y adhesión 
por la Asamblea General en su resolución 2200 A (XXI), de 16 de diciembre de 1966, (s/f) Recuperado de https://www.ohchr.org/sp/ professionalinterest/pages/cescr.aspx

Ramírez López, C., \& Ramírez Leyva, E. (Comp.). (2001). Los archivos y el conocimiento, los archivos y la educación. XIX Memoria del Coloquio Internacional de Investigación Bibliotecológica e Información. México D.F., México: Creative Commons.

Rubio Hernández, A. (2005). Aplicativos de Investigación Archivistica. Cali, Colombia: Universidad del Valle. [Entrada en vigor: 3 de enero de 1976, de conformidad con el artículo 27] 
